\title{
Model College Entrance Examination Scores as Predictors of Students' Performance in Junior Secondary Certificate Examination in Mathematics and English Language in Abia State, Nigeria
}

\author{
Opara Ijeoma Margaret", Umunna Ijeoma Happiness \\ Department of Educational Psychology, Guidance and Counselling, Faculty of Education, University of Port Harcourt \\ *Corresponding author: ijeomaopara64@yahoo.com
}

Received April 11, 2019; Revised May 19, 2019; Accepted June 17, 2019

\begin{abstract}
The study investigated model college Entrance Examination scores as predictors of students' performance in Junior Secondary Certificate examination in Mathematics and English Language in Abia State, Nigeria. Four research questions and four null hypotheses guided the study. The design of the study is correlational. A sample size of 500 students drawn from four (4) out of six (6) Model State Secondary Schools in Umuahia North Local Government Area through simple, stratified and purposive sampling techniques was used for the study. The students sat for both Model College Entrance Examination (MCEE) in 2011 and 2012 and Junior Secondary Certificate Examination (JSCE) in 2014 and 2015. The MCEE and JSCE results in mathematics and English language were used for data collection. Simple regression Analysis of Variances (ANOVA) and t-test associated with the regression were used to test the null hypotheses at 0.05 alpha level. The results revealed that the students' scores in MCEE in both mathematics and English Language in 2011 had significant predictive powers on their performance in 2014 JSCE. Also in 2012, it was realized that students MCEE scores in both Mathematics and English Language had no significant predictive powers on students' performances in 2015 JSCE in both subjects. On the basis of these findings, it was recommended among others that teachers should give adequate preparation to the students for the Model College Entrance Examination in order to retain consistency in their Junior Secondary Certificate Examination.
\end{abstract}

Keywords: Model College Entrance Examination, Junior Secondary Certificate Examination, predictors, performance, Mathematics and English language

Cite This Article: Opara Ijeoma Margaret, and Umunna Ijeoma Happiness, "Model College Entrance Examination Scores as Predictors of Students' Performance in Junior Secondary Certificate Examination in Mathematics and English Language in Abia State, Nigeria." American Journal of Educational Research, vol. 7, no. 6 (2019): 392-397. doi: 10.12691/education-7-6-3.

\section{Introduction}

Academic performance is a vital tool in the measurement of the academic achievement of students during or on the completion of a programme. According to Hornby [1] performance is how well or badly one does something or how well or bad something works. It is an act or process of performing a task, or an action which involves a lot of efforts or trouble. Jo [2] defined academic performance as the achievement of the student in terms of aggregates obtained in a test or examination in specific subjects that cover a given academic programme. Adeyemi [3] describes academic performances as the scholastic standing of a student at a given moment that could be explained in terms of the grades obtained in a course or group of courses. Umude [4] sees academic performance as a measure of the ability of a learner to recall appropriate learned fact and information at a particular time. It is however assumed that the degree of recalling learned experiences often depend on some environmental factors. Academic performance relates to the degree of efforts students put towards academic success.

Academic performances of students have over the years attracted much attention. This is evidence of the poor level of performance as well as fallen standard of students' academic achievement and attainments. The continuous repetition of classes by students and the significant low performances in general examinations also attract attention. Most people know that academic performance generally refers to how well a student is accomplishing his or her tasks and studies, but there are quite a number of factors that may determine the level and quality of students' academic performance. According to Bell [5], educational institutions success is measured by academic performance or how well a student meets standards set out by the institution itself. 
Academic performance is commonly measured by examinations. Examination among other things occupies the most important position in our educational system. Asuru [6] defined examination as the assessment of an examinee's ability, performance, achievement in a given task or subject. He further stated that examination assesses the testee's performance when he is confronted with series of questions, problems, tasks, situations etc. The results of such examination represents an estimate of the testee's behaviour (achievement, ability, skill, performance) and such results are required to make important decisions about the testees [7]. Elvis [8] explained that examinations are used to identify and define those adjudged suitable to proceed to the next level of education. Maduabum and Maduabum [9] view examination as an indispensable instrument in educational enterprise. They further state that examination serves as a tool for providing accountability of educational outcome and a basis for successive improvement of educational programmes. Examination plays a significant role in all aspects of education which can be in different forms and purpose to determine achievement of educational objectives at both formative and summative levels. Also examination is a yardstick or medium for academic status upliftment while some see it as an organized assessment technique towards ascertaining the individuals acquired skills effectively.

Model College Entrance Examination (MCEE) in Nigeria is the final year examination taken by students in their final year of primary school to gain admission into model secondary school in Nigeria. The MCEE is conducted by the Examination Development Centre (EDC). Model College Entrance is a crucial examination for students who seek admission into mode/federal colleges in Nigeria. There are different entrance routes depending on the type of secondary school one wish to attend in Nigeria. Basically, common entrance examination can be categorized into Model, National and State common entrance for admission into model, state and private secondary schools in Nigeria.

Junior Secondary Certificate Examination (JSCE) is a public examination conducted by each state of the federation through their respective Ministry of Education for final year students of the Junior Secondary School at the end of their Junior Secondary Education. Each state develops, administers, marks and award grades and certificate to all public schools under its jurisdiction. The Junior Secondary education provides both vocational and academics programmes for the students to enable them acquire knowledge and skills that will help them to make appropriate choice of career in the future [10]. At the end of the junior secondary education, the JSCE is conducted as a summative evaluation for the students to determine their level of academic and vocational achievement.

The subject scope of the study embraced some of the core subjects in Model College Entrance Examination (MCEE) and Junior Secondary Certificate Examination (JSCE) which are Mathematics and English Language. Mathematics is significant in our daily life. It has been stated that without mathematics there cannot be any current creates society. This accounts for the reason why mathematics is made a compulsory subject at the primary and secondary school levels in Nigeria [11]. Mathematics is an imperative school subject since it is connected with more scholastic as well as career opportunities [12]. Burton cited in Agwagah and Usman [13] relate the importance of mathematics to the scientific, industrial, technological and social programme of a society. All these account for the reason why mathematics is made compulsory at the first and the second level of education.

Interestingly, English Language is the medium of communication for all school subjects starting from the primary school to the college irrespective of the fact that most students find it difficult. It remains an obligatory school subject that must be passed at all levels of instruction in Nigeria [14]. The poor performance of our students in English Language in public examinations lately has been identified as a main reason why there is a decrease in scholastic performance as well as in the standard of instruction in Nigeria [15]. The reason may be attributed to their inefficiencies in the understanding and use of English Language as a medium of guideline which may have negative outcomes on their general scholastic performance. He further states that when understanding is insufficient in the language, this implies that the student would not perform well in the different school subjects taught using such language.

Observation has shown that for the past years, there has been mass failure of students every year when Junior Secondary School Certificate results were released in Abia State. It is obvious that these students who sat for the JSCE were the same students who went through Model College Entrance Examination and were admitted into JSS1. Once a student passes the model college entrance examination, it is expected that such student will do well in the junior secondary school certificate examination. However, this is not always the case as some students who passed very well in the MCEE find it difficult to cope at the JSCE. To this end, the researchers deemed it necessary to investigate if Model College Entrance Examination scores are good predictors of students' performance in Junior Secondary School Certificate Examination in Mathematics and English Language.

To guide the course of the investigation in this study, the following research questions were answered.

1. To what extent do 2011 MCEE Mathematics scores predict 2014 JSCE scores in Mathematics?

2. To what extent do 2011 MCEE English language scores predict 2014 JSCE scores in English language?

3. To what extent do 2012 MCEE Mathematics scores predict 2015 JSCE scores in Mathematics?

4. To what extent do 2012 MCEE English language scores predict 2015 JSCE scores in English Language?

The following null hypotheses tested at 0.05 level guided the study.

1. The 2011 MCEE Mathematics scores do not significantly predict 2014 JSCE scores in Mathematics.

2. The 2011 MCEE English Language scores do not significantly predict 2014 JSCE scores in English Language.

3. The 2011 MCEE Mathematics scores do not significantly predict 2015 JSCE scores in Mathematics.

4. The 2011 MCEE English Language scores do not significantly predict 2015 JSCE scores in English Language. 


\section{Methods}

The study was conducted using correlational research design. A correlational design is concerned with the determination of degree of relationship between two or more variable. Kpolovie [16] defined correlational design as a design which investigates the magnitude and direction or nature (positive or negative) of relationship that exists between a dependent variable and one or more independent variables. The population of the study consists of all the Model Secondary School students in Umuahia North Local Government Area of Abia State who sat for Model College Entrance Examination (MCEE) in 2011 and 2012, Junior Secondary Certificate Examination (JSCE) in 2014 and 2015. At the time of the study, there were 3649 students who sat for both MCEE and JSCE in 2011 to 2015 respectively. (Source: Ministry of Education and Examination Development Centre, Umuahia 2016). The representative sample for this study was 500 students drawn from four (4) out of six (6) Model State Secondary Schools in Umuahia North Local Government Area through simple, stratified and purposive sampling techniques. The data used for this study were the 2011 and 2012 MCEE Mathematics and English Language results and 2014 and 2015 JSCE Mathematics and English Language results which were collected from the statistical departments of the four model state secondary schools used in the study. The researchers adopted the simple regression analysis to answer the research questions while Analysis of Variance (ANOVA) and t-test values associated with the regression were used to test the null hypotheses at 0.05 alpha level.

\section{Results}

Research Question 1: To what extent do 2011 MCEE mathematics scores predict 2014 JSCE mathematics scores?

Hypothesis: The 2011 MCEE mathematics scores do not significantly predict JSCE 2014 scores in mathematics.

In order to answer the research questions, simple regression was employed while testing the null hypothesis Analysis Of Variance (ANOVA) and t-test associated with the regression were employed.

Table 1 reveals that the simple regression yielded a coefficient of $0.209, \mathrm{R}^{2}$ of 0.044 , adjusted $\mathrm{R}^{2}$ of 0.036 and standardized error of the estimate of 12.894. Based on $\mathrm{R}^{2}$, it indicates that 2011 MCEE mathematics scores predict only $4.4 \%$ of the students performance in 2014 JSCE mathematics. However, to determine if the prediction is significant or not, Analysis of Variance (ANOVA) associated with the simple regression was employed. The calculated F-value of 5.606 was significant at 0.019 which is less than the chosen alpha level of $0.05 \quad(p<0.05)$. Hence, the null hypothesis is rejected indicating that 2011 MCEE mathematics scores significantly predict students performance in 2014 JSCE mathematics. For further confirmation of the prediction of students performance in 2014 JSCE mathematics by their performance in 2011
MCEE mathematics, the t-value associated with the regression was also used. The table also shows that its tvalue of 2.368 was significant at 0.019 level which is less than the chosen probability level of $0.05(\mathrm{p}<0.05)$.

Therefore, the null hypothesis of no significant prediction of students' performance in 2014 JSCE mathematics by their 2011 MCEE mathematics is rejected. That means that students' performance in 2011 MCEE mathematics significantly predict their performance in 2014 JSCE mathematics in Umuahia North L.G.A of Abia State. The regression equation for students' performance in JSCE mathematics if $\mathrm{Y}=37.83+.185 \mathrm{x}$, where $\mathrm{x}$ is the raw score for each student in MCEE mathematics.

Research question 2: To what extent do 2011 MCEE English language scores predict 2014 JSCE English language scores?

Hypothesis 2: The 2011 MCEE English language scores do not significantly predict JSCE 2014 scores in English language.

In order to answer the research questions, simple regression was used while testing the null hypothesis ANOVA and t-test associated with the regression were employed.

Table 2 shows that the simple regression yielded a coefficient of $0.188, \mathrm{R}^{2}$ of 0.035 , adjusted $\mathrm{R}^{2}$ of 0.027 and standard error of the estimate of 10.806 . Based on $R^{2}$, it reveals that 2011 MCEE English Language scores predict only $3.5 \%$ of the students' performance in 2014 JSCE English Language. However, to determine if the prediction is significant or not, Analysis of Variance (ANOVA) associated with the simple regression was employed. The calculated F-value of 4.484 was significant at 0.036 which is less than the chosen alpha level of 0.05 $(\mathrm{p}<0.05)$. Hence, the null hypothesis is rejected indicating that 2011 MCEE English language scores significantly predict students' performance in 2014 JSCE English language. For further confirmation of the prediction of students' performance in 2014 JSCE English language by their performance in 2011 MCEE English language, the t-value associated with the regression was also used. The table also shows that the beta value of .188 which was significant at 0.036 level which is less than the chosen probability level of $0.05(\mathrm{p}<0.05)$. Therefore, the null hypothesis of no significant prediction of students' performance in 2014 JSCE English language by their 2011 MCEE English language is rejected. This implies that students' performance in 2011 MCEE English language significantly predict their performance in 2014 JSCE English language in Umuahia North L.G.A of Abia State. The regression equation for students' performance in JSCE English language is $\mathrm{Y}=58.284+.152 \mathrm{x}$, where $\mathrm{x}$ is the raw score for each student in MCEE English language.

Research question 3: To what extent do 2012 MCEE mathematics scores predict 2015 JSCE mathematics scores?

Hypothesis 3: The 2012 MCEE mathematics scores do not significantly predict JSCE 2015 scores in mathematics.

In order to answer the research questions, simple regression was employed while testing the null hypothesis ANOVA and t-test associated with the regression were employed. 
Table 1. Simple regression analysis of students' scores in 2011 MCEE mathematic as predictor of their 2014 JSCE scores in mathematics

\begin{tabular}{|ccccccc|}
\hline $\mathrm{R}=0.209$ & & & & & \\
$\mathrm{R}^{2}=0.044$ & & & & \\
Adjusted $\mathrm{R}^{2}=0.036$ \\
Std Error of Estimate $=12.894$ \\
Analysis of Variance (ANOVA)
\end{tabular}

a Dependent Variable JSCE.

Table 2. Simple regression analysis of students' scores in 2011 MCEE English language as predictor of their 2014 JSCE scores in English language

\begin{tabular}{|c|c|c|c|c|c|c|}
\hline \multicolumn{7}{|c|}{$\begin{array}{l}\mathrm{R}=0.188 \\
\mathrm{R}^{2}=0.035 \\
\text { Adjusted } \mathrm{R}^{2}=0.027 \\
\text { Std Error of Estimate }=12.894 \\
\text { Analysis of Variance }(\text { ANOVA) }\end{array}$} \\
\hline & Sum of squares & Df & Mean square & $\mathrm{F}$ & Sig. & Result \\
\hline Regression & 529.426 & 1 & 529.426 & 4.484 & 0.036 & Significant \\
\hline Residual & 14521.374 & 123 & 118.060 & & & \\
\hline Total & 15050.800 & 124 & & & & \\
\hline \multirow[t]{2}{*}{ Model } & \multicolumn{2}{|c|}{ Unstandardized coefficients } & Standardized coefficients & $\mathrm{t}$ & Sig. & \\
\hline & B & Std Error & Beta & & & \\
\hline Constant & 58.284 & 5.305 & & 10.987 & .000 & \\
\hline MCEE & .152 & .072 & -.188 & -2.118 & .036 & \\
\hline
\end{tabular}

Table 3. Simple regression analysis of students' scores in 2012 MCEE mathematic as predictor of their 2015 JSCE scores in mathematics

\begin{tabular}{|c|c|c|c|c|c|c|}
\hline \multicolumn{7}{|c|}{$\begin{array}{l}\mathrm{R}=0.005 \\
\mathrm{R}^{2}=0.000 \\
\text { Adjusted } \mathrm{R}^{2}=0.008 \\
\text { Std Error of Estimate }=10.421 \\
\text { Analysis of Variance (ANOVA) }\end{array}$} \\
\hline & Sum of squares & $\mathrm{Df}$ & Mean square & F & Sig. & Result \\
\hline Regression & 0.272 & 1 & 0.272 & 0.003 & 0.960 & Insignificant \\
\hline Residual & 13356.928 & 123 & 108.593 & & & \\
\hline Total & 13357.200 & 124 & & & & \\
\hline \multirow[t]{2}{*}{ Model } & \multicolumn{2}{|c|}{ Unstandardized coefficients } & Standardized coefficients & $\mathrm{t}$ & Sig. & \\
\hline & B & Std Error & Beta & & & \\
\hline Constant & 48.921 & 4.914 & & 9.955 & .000 & \\
\hline MCEE & .003 & .068 & -.005 & -.050 & .960 & \\
\hline
\end{tabular}

Table 3 reveals that the simple regression yielded a coefficient of $0.005, \mathrm{R}^{2}$ of 0.000 , adjusted $\mathrm{R}^{2}$ of 0.008 and standardized error of the estimate of 10.421 . Based on $\mathrm{R}^{2}$, it showed that 2012 MCEE mathematics scores have no predictive power at all on 2015 JSCE scores in mathematics. In testing the hypothesis, ANOVA associated with the simple regression was used. The calculated Fvalue of 0.003 was significant at 0.960 which is greater than the chosen probability level of 0.05 ( $p>0.05)$. Hence, the null hypothesis is retained indicating that $2012 \mathrm{MCEE}$ mathematics scores did not significantly predict students' performance in 2015 JSCE mathematics. For further confirmation of the prediction of students' performance in 2015 JSCE mathematics by their performance in 2012
MCEE mathematics, the t-value associated with the regression was also used. The table also revealed that the beta value of -.005 which was not significant based on its t-value of -.050 , was significant at .960 level which is greater than the chosen probability level of 0.05 ( $p>0.05)$.

Therefore, the null hypothesis of no significant prediction of students' performance in 2015 JSCE mathematics by their 2012 MCEE mathematics is retained. That means that 2012 MCEE mathematics scores did not significantly predict students' performance in 2015 JSCE in mathematics in Umuahia North L.G.A of Abia State. The regression equation for students' performance in JSCE mathematics is $\mathrm{Y}=48.921+.003 \mathrm{x}$, where $\mathrm{x}$ is the raw score for each student in MCEE mathematics. 
Table 4. Simple regression analysis of students' scores in 2012 MCEE English language as predictor of their 2015 JSCE scores in English language

$\mathrm{R}=0.021$

$\mathrm{R}^{2}=0.000$

Adjusted $\mathrm{R}^{2}=0.008$

Std Error of Estimate $=9.235$

Analysis of Variance (ANOVA)

\begin{tabular}{|c|c|c|c|c|c|c|}
\hline & Sum of squares & Df & Mean square & $\mathrm{F}$ & Sig. & Result \\
\hline Regression & 4.705 & 1 & 4.705 & 0.055 & 0.815 & Insignificant \\
\hline Residual & 10490.447 & 123 & 85.288 & & & \\
\hline Total & 10495.152 & 124 & & & & \\
\hline \multirow[t]{2}{*}{ Model } & \multicolumn{2}{|c|}{ Unstandardized coefficients } & Standardized coefficients & $\mathrm{t}$ & Sig. & \\
\hline & B & Std Error & Beta & & & \\
\hline Constant & 48.710 & 5.305 & & 9.550 & .000 & \\
\hline MCEE & -.016 & .069 & -.021 & -.235 & .815 & \\
\hline
\end{tabular}

Research question 4: To what extent do 2012 MCEE English language scores predict 2015 JSCE English language scores?

Hypothesis 4: The 2012 MCEE English language scores do not significantly predict 2015 JSCE English language scores.

In order to answer the research questions, simple regression was employed while testing the null hypothesis ANOVA and t-test associated with the regression were used.

Table 4 reveals that the simple regression yielded a coefficient of $0.021, \mathrm{R}^{2}$ of 0.000 , adjusted $\mathrm{R}^{2}$ of 0.008 and standard error of the estimate of 9.235 . Based on $\mathrm{R}^{2}$, it showed that 2012 MCEE English Language scores have no predictive power at all on 2015 JSCE English Language scores.

In testing the hypothesis, ANOVA associated with the regression was employed. The calculated F-value of 0.055 was significant at 0.815 which is greater than the chosen probability level of $0.05 \quad(p>0.05)$. Hence, the null hypothesis is retained indicating that 2012 MCEE English language scores did not significantly predict students' performance in 2015 JSCE English language. For further confirmation of the prediction of students' performance in 2015 JSCE English language by their performance in 2012 MCEE English language, the t-value associated with the regression was also used. The table also revealed that the beta value of 0.021 which was not significant based on its t-value of 0.235 , was significant at 0.815 level which is greater than the chosen alpha level of $0.05(\mathrm{p}>0.05)$.

Therefore, the null hypothesis of no significant prediction of students' performance in 2015 JSCE English language by their 2012 MCEE English language is retained. This implies that students' performance in 2012 MCEE English language scores did not significantly predict their performance in 2015 JSCE English language in Umuahia North L.G.A of Abia State. The regression equation for students' performance in JSCE English language is $\mathrm{Y}=48.710+-0.016 \mathrm{x}$, where $\mathrm{x}$ is the raw score for each student in MCEE English language.

\section{Discussion of Findings}

In 2011, it was found out that the students' scores in MCEE in both mathematics and English Language had significant predictive powers on their performance in 2014 JSCE. The result means that all the students who sat for both subjects in their MCEE and scored well also sat for JSCE in 2014 and scored well too. On the other hand, those who performed poorly in 2011 MCEE significantly performed poorly in 2014 JSCE. The findings here may come because the students may have learnt from previous mistakes, past questions and answers as well as other experiences that may keep them informed on what to do in order to repeat success in higher classes. The finding is of course expected because good performance in an area may produce better in another. This finding is in line with that reported by Osadebe [17] who noted that there was a positive relationship between JSCE and SSCE scores in Mathematics and English Language.

In 2012, it was realized that students MCEE scores in both mathematics and English Language had no significant predictive powers on students' performance in 2015 JSCE in both subjects. The results indicated zero (0) percentage. It represents an astonishing report to the researchers because the previous year being 2011 indicated a significant prediction. The result may arise because a lot of students may have either lost focus or may improve on their performance in the first instance if students that were brilliant and performed well in the MCEE in both subjects, decide to let the influence of friends to affect them negatively, then such students will experience inconsistency in their results from good to bad. On the other hand, if a student who sat for the MCEE with poor grades decide to sit up and read, such positive decision will also lead to inconsistency in the two scores (MCEE in 2011 and 2015 JSCE). This result is in agreement with the works of Kolawole, Ala and Olatunji [18] who found out that Common Entrance Examination (CEE) had low, negative and not statistically significant to Secondary School Certificate Examination (SSCE). However, the findings negate the findings of Kolawole \& Ilugbusi [19] who found out that there is a significant linear relationship between entry qualification and their achievement in the universities. The divergent in the results may be attributed to the variance in the area of the study and the respondents used. 


\section{Conclusion}

Model College Entrance Examination (MCEE) had significant predictive powers on students' performance in 2014 Junior Secondary Certificate Examination. On the other hand, it did not significantly predict student's performance in 2015 Junior Secondary Certificate Examination. This implies that when students are very serious in their studies it must surely reflect in their performance and vice-versa.

\section{Recommendations}

Based on the findings of the study, the following recommendations were made.

1. Students at every point in time should study to maintain positive consistency in their performance. They should not be over taken by early success neither should they bank on past glory based on their previous academic achievement.

2. Teachers as well as guidance counsellors should ensure that students' interest in every subject is sustained. They should discourage all forms of dislike for any particular subject whether Mathematics that is generally perceived as difficult or English Language.

3. Teachers should give adequate preparation to the students for the Model College Entrance Examination in order to retain consistency in their Junior Secondary Certificate Examination.

\section{References}

[1] Hornby, A.S. (2004). Oxford advanced learner's dictionary. London: Oxford University Press.

[2] Joe, A. I. (2011). Basic concepts of educational measurement and evaluation. Port Harcourt: Paragraphics.

[3] Adeyemi T. O. (2001). A comparative study of students' academic performance in public examinations in secondary schools in Ondo and Ekiti States, Nigeria. Current Research Journals of Economic Theory, 3 (2), 36-42.

[4] Umude, O. S. (2010). The psychological problem influencing academic performance of Junior secondary school students in Rivers State. Unpublished M. Ed thesis, University of Port Harcourt, Nigeria.

[5] Bell, B. (2000). Teacher development in science education. International Handbook for science Education part two. Kluver: Academic publishers.

[6] Asuru, V. A. (2008). Examination malpractice: Agenda for a change Port Harcourt: Owas Publishers.

[7] Owolabi, H. O. (2004). Public examination in Nigeria. Journal of Educational Research and Evaluation 5(1), 97-101.

[8] Elvis, A. L (2003). Essential of educational measurement, $\left(3^{\text {rd }}\right.$ ed) New Jersey, Eaglewood Cliffs: Prentice Hall Inc.

[9] Maduabum, C.I \& Maduabum, M.A (2000). Examination malpractice and standards. Reflection on society, Institution teacher related factors. Ankpa: Cuca Ltd.

[10] Opara, I. M. \& Chilee, S. U. (2017). Basic science Junior School Certificate examination as predictor of senior school certificate examination in physics, chemistry and biology in Aba metropolis of Abia State Nigeria. IOSR Journal of Research and method in Education (10SR-JRME) 7(6); 32-38.

[11] Federal Republic of Nigeria (2008). National policy on Education. Lagos: NERC press.

[12] Akinsola, M. K. \& Tella, A (2003). Correlates of academic procrastination and mathematics achievement of university of undergraduate students. Eurasia Journals of mathematics, Science \& Technology Education 3(4), 363-370.

[13] Agwagah, U. \& Usman (2003). Guidance and Counselling a functional approach. Lagos; John Lab Enterprises.

[14] Ayodele, S. O. (2012). The use of English in educating Nigerian youths: From the problem to the solution, An inaugural lecture, University of Ibadan, Ibadan.

[15] Feast, L. N. (2002). Behavioural research: Theory, procedure and design. San Francisco: Freeman.

[16] Kpolovie, P. J. (2010). Advanced research methods. Owerri: Spring Field Publishers Ltd.

[17] Osadebe, P. U. (2003). Predictive validity of junior secondary certificate examination for senior secondary school certificate examination. Journal of Educational Research and Development, 2(1); 183-188.

[18] Kolawole, E. B.; Ala, E. A.O. \& Olatunji, O. A. (2014). Previous cognitive entry points as predictors of students' performance in senior school certificate examination (SSCE) mathematics in some Nigerian Secondary schools. Education Research Journals, 4(1); 7-11.

[19] Kolawole, E. B. \& Ilugbusi, A. A (2007). Cognitive entry grades as predictors of students academic performance in mathematics in Nigerian university. Medwell Journals 2(3); 322-326. 